\title{
Agradecimento do Professor Miguel Reale*
}

\section{"MINHA TRAJETÓRIA UNIVERSITÃRIA"}

Esta não é uma noite de despedida. Trata-se, ao contrário, de uma noite destinada ao retorno às raizes mais puras de nossa sensibilidade, uma cerimônia de volta àquilo que é mais significativo em nós mesmos, porquanto - para mim, pelo menos - representa um retorno ao meu tempo de estudante, quando, inquieto e sobressaltado como todos os calouros que adentram pelo futuro, cruzei os pórticos das Arcadas, vendo, de um lado, os nomes dos poetas, e, do outro, os dos juristas.

Senti, naquele instante, que não sabia direito o que estava procurando, se as ciências jurídicas ou as belas letras, ficanảo, desde então, tentado a vivê-las, conjuntamente, em sua possível sintonia.

Porque, naquela época -1930 - a nossa Faculdade era o centro humanístico de São Paulo, uma vez que ainda não existia, Magnífico Reitor, a Universidade de São Paulo, com a Faculdade de Filosofia, Ciências e Letras que veio completar o florilégio da cultura brasileira.

Entrei em 1930; o ano da expectativa nacional. Desde então, a minha vida não se separou jamais desta Casa. Como, depois, não iria se separar, nunca, da Universidade de São Paulo.

Essa Universidade eu a encontrei bem mais tarde, em minha vida política. Quando se tratou de dar-lhe plena autonomia administrativa, coube-me a alegria, como membro do Conselho Administrativo do Estado, de votar o Decreto-lei que transformava a USP em insti uição autárquica e, ao mesmo tempo, lhe conferia, Magnífico Reitor, todas as atribuições do antigo Secretário de Educação, nos assuntos pertinentes ao ensino superior. Como esse Decreto-lei até hoje não foi revogado, Deus queira que venha a ser cumprido, como o foi no passado, asseguradas ao Reitor todas as prerrogativas de Secretário de Estado, tal como a dignidade da USP o exige.

Mas, ao me matricular nesta Faculdade, há mais de cincoenta e dois anos, só estava certo de uma coisa: de que ia encontrar uma Casa da tradição, dessa tradição autêntica que jamais se contenta

* Reconstituído segundo gravação. 
consigo mesma, porque procura, a todo instante, criar e constituir valores novos, projetando-se e consolidando-se no futuro.

Mas 1930 foi o ano da revolução brasileira, daquela revolução que, sem dúvida alguma, marcou o início de uma nova fase na vida nacional, pelo advento de novos elementos e valores sociais. Isto nós o sentimos, em nossa turma, a começar pelo até então inédito afluxo da massa universitária. Éramos 235 estudantes - quase tantos quanto os que compunham as quatro outras séries. Começava, assim, a chegada do "homo novus" que iria transformar a feição de nossa sociedade, ainda agrícola e patriarcal.

Não foi por acaso que a Revolução de 1930 tomou caminhos imprevistos, obedecendo aos sinais do tempo, que eram de renovação e de procura de novos rumos, surpreendendo aqueles que a haviam deflagrado em nome de um liberalismo por demais confiante em suas fórmulas salvadoras, mas que não penetravam até o âmago da problemática econômico-social.

Vivi intensamente o drama de minha geração. Bem cedo, acentuaram-se em meu espírito a preocupação filosófica e a política, uma inseparável da outra, porque há momentos em que a política se faz filosofia e a filosofia se faz política, quando está em jogo o destino do homem, e o intelectual não pode ficar encantado contemplando suas próprias idéias, friamente distante da experiência social e histórica.

A nacionalidade brasileira encontrava-se perplexa ante um leque de possibilidades, exigindo corajosas opções, especialmente por parte dos moços. Nessa conjuntura, de tudo poderei ser acusado, menos de uma coisa: de ter sido omisso.

Procurei, ao contrário, compreender e acompanhar, um a um, os acontecimentos de minha terra. Não vai nenhuma vaidade fátua nisso. Nos velhos e nas mulheres belas a vaidade é perdoável. E eu tenho vaidade de ter sido um jovem de olhos abertos para os problemas do mundo e de mim mesmo.

Poderei ter errado, pois foi através dos erros que procurei me corrigir; e foi através dos erros que fui adquirindo a compreensão humanística a que se referiu, com tanta sensibilidade, esse que é um dos meus mais notáveis ex-discípulos, Tércio Sampaio Ferraz Júnior.

Passaram-se os anos de aprendizado na Faculdade de Direito de São Paulo quando sobreveio a Revolução de 32; e me coube ser soldado, no grau de $3^{\circ}$ sargento, da chamada "Guerra Paulista". Eu não sei bem o que foi que me levou a alistar-me como revolucionário. Não foi, sem dúvida nenhuma, o amor a um ideal puramente formal de democracia. Mas foi, talvez, e acima de tudo, o desejo comunitário de estar em consonância com a gente paulista, então injustamente injustiçada. Razão pela qual ao escrever, ainda estudante, o meu primeiro livro, "O Estado Moderno", fiz questão de que, no frontispício 
dessa obra, figurasse o nome de dois colegas mortos em $32 . \mathrm{E}$ jamais isto se me apagou da memória. Foi um compromisso assumido com a juventude de meu tempo, um compromisso assumido com minha gente.

É possível que essa tenha sido uma das razões que me levaram a indagar dos fundamentos lógicos e morais do Direito, orientando-me para a Filosofia Jurídica, - disciplina que não se estudava, naquela época, em nossa Academia. $O$ estudo introdutório fazia-se apenas através do Direito Romano, cuidando-se mais de sua "história externa".

Mas, meus caros amigos e doutos colegas, foi um periodo muito curto na história de nossa Faculdade e do alheamento à Filosofia Jurídica. Esta Casa, ao contrário, tem a tradição dos estudos filosófico-jurídicos. Se no pórtico há três nomes de poetas e três de juristas, no relicário da Faculdade, todavia, há três salas de aula que, para mim, representam o coração desta Casa: as salas João Arruda, Pedro Lessa e João Mendes de Almeida Júnior. Três cultores do Direito e da Filosofia Jurídica, retomando uma velha tradição que surgiu desde o tempo de Avelar Brotero - o primeiro mestre da disciplina que, então, se denominava Direito Natural e das Gentes.

Mas houve um triste período em que, não obstante o brilho extraordinário das lições de Pedro Lessa, o imediatismo de alguns ou uma falsa compreensão da ciência pretendeu afastar a Filosofia do Direito, para substituí-la pela Enciclopédia Jurídica. João Mendes Júnior, com mordacidade, dizia que era a arte de se ensinar de cada coisa um pouco, e de tudo, nada. E João Arruda, com o seu espírito desabusado e franco, proclamava: - "A lei me manda ensinar Enciclopédia Jurídica; pois eu, não sabendo o que é isso, vou lecionar mesmo é Filosofia do Direito!"

Uma das glórias da Faculdade de Direito do Largo de São Francisco é ter sabido manter-se fiel à Filosofia Jurídica, o que aumentava minha responsabilidade de jovem professor, quando, após agitados episódios, pretei meu compromisso de catedrático. Tinha pouco mais de 31 anos e uma fé inabalável nos valores da educação e da cultura, um entusiasmo pela Filosofia do Direito, desde então já entendida como um estudo vinculado às forças vivas da experiência.

Compreenderá, portanto, meu caro amigo Bernardo Cabral, com que entusiasmo tive conhecimento de que Vossa Excelência na qualidade de Presidente do Conselho da Ordem dos Advogados do Brasil, procurara o Ministro de Estado da Educação e Cultura a fim de reclamar o ensino obrigatório da Filosofia do Direito em todas as Faculdades do País.

Não julgueis, no entanto, que, ao falar assim, esteja tocado por uma idolatria. Não julgueis que esteja insulado no culto de minha própria disciplina. Não, não é isso. É que eu sinto cada vez mais em causa e em crise a vida jurídica, por lhe faltar o sustentáculo resultante da meditação de seus fundamentos sociais e éticos. 
Todos nós sentimos que a vida contemporânea está marcada pela orgia do dinamismo e da sofreguidão. Há pessoas para as quais não existe nada de significativo que não tenha o marco da técnica e do racionalismo abstrato. Mas o racionalismo abstrato e a técnica miúda e pragmática têm comprometido o destino do homem. Tem razão, assim, um dos maiores mestres do pensamento contemporâneo, Edmund Husserl, quando adverte que a crise da ciência atual não é uma crise de método, nem resulta de problemas epistemológicos, mas, pura e simplesmente, é uma crise de consciência histórica e sobretudo de consciência humanística, por não se cuidar do significado da ciência para o homem.

Assim sendo, compreendeis bem como a referência feita por Tércio Sampaio Ferraz Júnior ao sentido humanístico que procurei imprimir à minha vida, me tocou profundamente. Estou convencido de que esse é um dos pontos capitais em jogo no destino do homem. Em verdade, se Husserl tem razão quando diz que o homem conquistou o saber da ciência mas não sabe o que fazer com ela, um outro filósofo, Edgar Morin, repete, como num eco trágico, que a ciência gerou um poder sobre o qual ela não exerce poder algum. Diante de ameaça tão profunda para todos os homens, é necessário que voltemos a meditar sobre o Direito e os seus fundamentos.

Se o Direito nasceu em Roma como ciência positiva, ela, na realidade, encontra a sua fonte inspiradora na meditação filosófica dos gregos. A bem ver, a Ciência Jurídica representou um desses matrimônios extraordinários, que se realizam de tempos a tempos, através do processo dialógico da História. É que houve o encontro do "logos" grego - da lucidez da razão e da compreensão racional do homem - com o sentido concreto da vida, da experiência vital, que nos legaram os romanos. E, assim, a "praxis" ou a "voluntas" romana se casava com o "logos" grego, para fazer surgir a nossa ciência, aquela que nesta noite estamos aqui homenageando.

Porque, compreendo-o perfeitamente, estamos reunidos em homenagem ao Direito e à Justiça, e não pela personagem transitória que vos fala. Não sou um protagonista do Direito, mas apenas um servo dele. Isto é que é essencial: não se julgar o mestre dono de nada, não se considerar senhor de nenhuma forma de saber, nem de nenhuma verdade prática, graças à compreensão de que nós, como professores, somos sempre alunos de um mestre só: do meditado no dia de hoje como preparo contínuo do dia de amanhã. Esse sentido de historicidade é que é fundamental para o homem contemporâneo. Porque a história não é a passagem transeunte e indiferente de segundos ou de anos. A história, ao contrário, é algo que reside em nosso próprio ser, na medida em que compreendemos que só há validade no ser humano enquanto ele se transcende.

Este momento mesmo, que me concedeis de vossa carinhosa atenção, não é de contemplação pura. Em verdade, cada idéia que 
trocamos, neste instante, já é um esboço de ação, superada que já foi a separação comprometedora que se levantou, no século passado, entre o pensamento e a atividade prática. Teoria e prática, ao contrário, se casam de maneira constante e essencial, o que demonstra que o jurista não pode se circunscrever ao imediatismo dos casos forenses, nem se perder em abstração desvinculadas da vida.

Se o Direito se reduzisse à prática forense, seria o caso de fecharmos as Faculdades de Direitos e arranjarmos emprego, para os estudantes, nos cartórios dos tribunais.

Não, não é do miúdo dos casos particulares que a Ciência Jurídica se ocupa, mas dos enlaces lógicos e éticos dos princípios, das idéias-forças que dão sentido tanto às decisões dos juízes, como às petições dos advogados, fazendo, de uns e de outros, instrumentos de um ideal mais alto.

Percebeis bem qual a missão que atribuo à nossa Faculdade de Direito, a qual nem por terem sido criados cursos de Filosofia e de Letras, poderá deixar de atuar de maneira permanente e fecunda nesses dois campos da atividade humana. Ainda, há poucos dias, passando em revista o cenário cultural e sobretudo literário de São Paulo, eu me perguntava: será que a época de Fagundes Varela, de Castro Alves e de Álvares de Azevedo já desapareceu? Eu comparava as obras dos representantes mais altos do romance e da poesia, da filosofia e das teorias políticas, hoje, em São Paulo, e verificava que a maioria deles ainda tem o seu berço, e espero continue a tê-lo, à sombra das Arcadas. A poesia jamais desertará desta Casa. Há, nas raízes do velho convento franciscano, algo de misterioso que leva os que estudam em contato com elas, a trilhar todos os caminhos da vida. Há algo de estranho na sombra das Arcadas que atrai o homem para o Direito, é certo, mas também para a diplomacia, para o romance, para a poesia, para o jornalismo e para a política, para onde quer que vibre um valor do homem enquanto homem.

A Faculdade de Direito jamais deveria deixar cair essa tocha fundamental de seu destino. Não quero lembrar, aqui, nomes dos grandes romancistas e poetas de nossos dias, que saíram das Arcadas. Lembro apenas, como símbolo, o nome daquele que é o patrono de todos os homens de Letras de São Paulo - Menotti del Picchia, cujo nome está faltando neste salão nobre.

Meus caros amigos, eu vos disse que encontrei a Universidade de São Paulo, como entidade e instituição, quando membro do Conselho Administrativo do Estado. E, desde então, criei um amor extraordinário por essa Universidade, dentro da qual a Casa do Direito não figura como mais um Instituto, mas sim como um Instituto que reivindica a sua posição histórica, sabendo, porém, que essa reivindicação só poderá ser legítima na medida em que se modernizar e se atualizar, acompanhando ritmo do tempo e os imperativos da ciência. 
Ora, quando me coube, muito jovem talvez, a responsabilidade de dirigir os destinos da Universidade de São Paulo, em 1949, encontrei-a ainda padecendo de muitos erros e equívocos. Talvez não se saiba que, naquela época, havia três categorias de professores, os de Direito, de Medicina, de Engenharia e Filosofia, no topo do firmamento universitário, e daí, numa gradação ou degradação que não tinha sentido, nem ético e nem cultural, seguiam os demais professores com três escalas de vencimentos. Mas a compreensâo, que sempre me animou, de que a cultura não obedece a tais discriminações e preconceitos ridículos, levou-me a propor, logo no início de minha gestão, ao Conselho Universitário que se proclamasse a igualdade de todos os mestres, porque todos nós somos iguais perante os valores da cultura.

Eis uma vaidade que eu tenho o direito de acalentar, recordando-a neste momento. A vaidade das decisões justas é compensada pelos erros que também sei confessar. $E$ os erros foram muitos. Erros, como Reitor da Universidade, eu os tive, e como não poderia ser de outro modo, em se tratando de uma instituição tão vasta, diversificada e poderosa, quando me cabia penetrar na consciência e nas intenções de homens de tantos e tão diferentes centros de aspirações e de interesses?

Mas procurei sempre - e meus colegas de Universidade felizmente o reconhecem - procurei sempre colocar-me na posição de outrem. Procurei seguir aquele que é o único caminho da compreensão - o de estender a mão ao próximo, ao alcance de nosso gesto, preferindo-o à humanidade distante, apenas uma abstração.

Desse modo, a Universidade se entranhou em meu destino. Coube-me voltar a dirigi-la, vinte anos depois - o que provocou a irônica observação de um estudante, de que eu era uma personalidade de Alexandre Dumas. - , coube-me volver à Reitoria em momentos mais delicados de sua existência, quando me competiu dar execução a uma reforma universitária com cujos objetivos não estava integralmente de acordo, mas que, por força de lei, me cumpria executar, com a colaboração e na medida compreensiva do Conselho Universitário. $\mathrm{E}$ foram dias de trabalho insano! Foram meses de extremada dedicação, felizmente correspondida pela compreensão de mestres, funcionários e alunos. Foi uma época em que foi necessário baixar Portarias atrás de Portarias, para que a reforma se transformasse em algo de concreto e de vivo. $\mathrm{E}$ eu aqui vos confesso: nem todas elas eram cem por cento legais do ponto de vista da competência, pois, a rigor, me via na contingência de dispensar a audiência prévia do Conselho Estadual de Educação, sob pena de tornar-se inviável a aplicação oportuna da lei. Em tais casos, pouco importa a legalidade estrita, quando o que está em jogo é um valor superior e urgente de ordem cultural.

Se amanhã um analista minucioso resolver esmiuçar Resoluções e Portarias, emanadas às vezes "ad referendum" do Conselho Univer- 
sitário, poderá encontrar nelas vícios formais. Mas o que não poderá encontrar jamais é uma violação do direito substancial, o repúdio ao direito real e concreto, que este é o que importa, e não as fórmulas e diagramas com que às vezes nos vemos impedidos de realizar a verdade ou a Justiça.

$\mathrm{E}$ a Universidade se projetou de maneira exemplar, auferindo da lei o que ela continha de melhor, graças ao potenciamento criador de seus Institutos, cuja unidade se apresenta como centro propulsor da cultura, não apenas de São Paulo e do Brasil, mas de toda a América Latina. O certo é que, na época, soubemos preservar o nosso sistema estadual de ensino, repelindo intromissões indébitas da órbita federal.

Tenho andado por aí afora, e tenho sentido o que significa a Universidade de São Paulo, que, nesta noite, fez questão de estar presente. Como a vossa presença me comove! Como toca profundamente a meu coração sentir que esta festa, que era da Faculdade de Direito, se transformou também em festa da Universidade de São Paulo!

Abstração feita de minha pessoa, como poderia ser diferente? Como conceber-se uma Faculdade de Direito como esta, que nasceu da História e é História, separada de sua Universidade, de uma Instituição que, nos seus breves anos de existência, em confronto com as velhas universidades européias, já realizou uma obra magnífica, digna da nossa maior admiração?

Estais vendo, meus caros amigos, que não vos está falando o filósofo do Direito, nem tampouco o professor. Preferi que falasse, apenas o homem, de alma aberta à vossa gentileza e à vossa compreensão. É que estamos aqui presentes, não fisicamente, mas em espírito, num sentido que transcende à nossa própria profissão, que ultrapassa o campo dos interesses particulares de cada um, por ser esta uma oportunidade de comungarmos com o pão da cultura.

Foi por essa razão, meus caros colegas universitários, que, ao concluir a minha tarefa na Universidade de São Paulo, ao levantar a Torre que simboliza o encontro das ciências humanas e das ciências naturais, sugeri que em torno dela se inscrevesse uma frase de sentido e inspiração pascaliana: "No universo da cultura, o centro está em toda parte". Ao propor essa frase, eu pensei num círculo ideal que abandonava o Butantã e se alargava para colher em suas malhas as doutas Faculdades de Direito, de Medicina e de Higiene e Saúde Pública, a então longínqua Faculdade de Odontologia, mais a Faculdade de Medicina Veterinária e todas as Unidades pujantes do Interior, para, após uma pausa reverente no Pátio do Colégio, volver ao ponto de partida, carregando esse patrimônio de ciência e de história que é apanágio da gente paulista.

Quando foi fundada esta Faculdade, já se pensava numa Universidade brasileira. O tempo ofereceu, porém, resistência a essa idéia, 
só concretizada em 1934; mas, antes dela, as Arcadas atuaram como centro universitário a seu modo, ultrapassando os domínios do Direito. $\mathrm{Na}$ realidade, delas saíram, como todos sabemos, a maioria dos grandes poetas, dos mais lúcidos políticos, dos mais argutos diplomatas, dos mais penetrantes juristas, dos mais atilados jornalistas de nossa pátria. Daqui saíram homens de todas as vibrações do espírito, em consonâncıa com as virtualidades de nossa gence. É o motivo pelo qual me limito a pedir ao Lauro Celidônio Neto, Presidente de nosso Centro Acadêmico XI de Agosto, que seja intérprete junto a seus colegas desta mensagem de um velho professor: "Nunca olvideis que esta é a morada do Direito e do Humanismo".

O Humanismo nasce da compreensão de que todos os valores só têm algum significado quando se fundam no valor primordial da pessoa humana, visto como o homem, consoante costumo dizer, é o único ser cujo ser é o seu dever ser originário, um ente que, para ser o que deve ser, constantemente se transcende.

De outro lado, não vos esqueçais, moços do Largo de São Francisco, que estas Arcadas continuam sendo uma Casa de São Francisco, cujo oitavo centenário este ano estamos comemorando. Pois bem, São Francisco fez a segunda revolução cristã, quando abriu o coração do homem para a natureza, quando descerrou o coração do homem para os animais mansos ou raivosos, quando compreendeu que é sempre bem vinda uma palavra de cordialidade e de amor. A grande sabedoria da Igreja foi receber em seu seio esse homem, que estava trazendo uma mensagem renovadora para todo o sempre e, num primeiro momento, parecia herético.

À luz dos ensinamentos franciscanos, compreendemos que a Justiça é uma virtude que não tem objeto próprio, porque é seu destino dar a cada um o que é seu, sendo, assim, uma virtude que só existe em função das demais virtudes. Essa é a lição franciscana da Justiça, como vivência amorosa do justo, o que faz meu pensamento volver a Dante, cujo nome quero lembrar neste momento, inclusive porque cresci sob o teto do Colégio Dante Alighieri. Foi com Dante que aprendi a cultivar a Axiologia, ao conceber ele Deus como Primeiro Valor, o que demonstra que para sabermos o que sejam os valores, devemos conhecer, primeiro, a resposta dos poetas.

Com estas invocações do poeta florentino e do "poverello" de Assis, quero encerrar minhas palavras. Nada mais se pode dizer, depois de Dante e de São Francisco de Assis. Para que mais falar, quando esses dois nomes enfeixam o que há de mais alto no espírito humano, quando esses dois nomes significam amor ao homem pelo que ele é, e amor ao homem porque ele é capaz de ser, realizando-se em comunhão com os outros, como em comunhão de espírito me sinto neste instante. 